\title{
Elaboração de Bolo sem Lactose com substituição Parcial da farinha de trigo por Pós-Alimentícios Obtidos De Resíduos De Goiaba Vermelha
}

\author{
SENA, D. N. ${ }^{1}$; ALMEIDA, M. M. B. ${ }^{2}$; SOUSA, P. H. M. ${ }^{3}$ \\ ${ }^{1}$ Aluna de graduação em Engenharia de Alimentos da UFC - Campus do Pici; \\ ${ }^{2}$ Docente da UFC - Campus do Pici, do Departamento de Química Analítica e Físico-Química \\ ${ }^{3}$ Docente da UFC - Campus do Pici, do Instituto de Cultura e Arte. \\ E-mail: deborasnascimento@gmail.com
}

\begin{abstract}
RESUMO - A lactose é um dissacarídeo hidrolisado pela enzima intestinal lactase na ausência desta enzima, a lactose é fermentada no cólon causando desconforto. Os resíduos provenientes do processamento de frutas compõem um material rico em componentes nutricionais que poderia ser utilizado na alimentação humana, com a finalidade de enriquecê-la. Assim, o presente trabalho buscou a elaboração de um novo produto alimentício com a adição de pó-alimentício proveniente de resíduos de processamento de goiaba. A farinha se mostrou favorável a comercialização e fonte de acido ascórbico. A analise sensorial demostrou uma maior aceitabilidade dos bolo com a substituição da farinha de trigo por pó-alimentício de resíduo de goiaba.
\end{abstract}

\section{INTRODUÇÃO}

A lactose, é um dissacarídeo, formado por glicose e galactose, hidrolisado pela enzima intestinal lactase, liberando seus componentes monossacarídicos para absorção na corrente sanguínea. Quando ocorre a falta desta enzima, a lactose, é fermentada a ácido láctico, metano (CH4) e gás hidrogênio (H2), produzido cria uma sensação de desconforto por distensão intestinal e pelo incômodo problema de flatulência (BARBOSA, 2011).

O consumo de frutas cada vez mais se torna crescente devido ao valor nutritivo e aos efeitos terapêuticos, (KUSKOSKI et al., 2006). Neste setor, além da demanda por frutas frescas é crescente o mercado de sucos e polpas. Como consequência, o aumento deste processamento gera cerca de $40 \%$ dos resíduos agroindustriais, composto de restos de polpa, casca, caroços ou sementes ( ABUD 2009). Estes resíduos podem, por sua vez, ser utilizados no desenvolvimento de novos produtos alimentícios, aumentando seu valor agregado, pois muitos deles são ricos em nutrientes minerais, fibra alimentar e compostos bioativos, amplamente reconhecidos pelas suas propriedades promotoras de saúde tais como antioxidantes e antimicrobianos (ABUD, 2009).

Os produtos da padaria são uma parte importante de uma dieta equilibrada (SILVA, 2009). Entre os produtos de panificação, o bolo vem adquirindo crescente importância no que se refere ao consumo e à comercialização no Brasil (MOSCATTO et al., 2004).

Considerando a escassez de dados sobre as características químicas de produtos obtidos a partir do resíduo de frutas, o presente trabalho busca desenvolver um produtos alimentícios, bolo tipo fofo, com 
adição de pó alimentício de resíduo de goiaba (Psidium guayaba L.). Além de caracterizar a qualidade físico-química do pó e realizar análise sensorial de aceitabilidade do produto nas diversas concentrações de pó adicionado.

\section{MATERIAL E MÉTODO}

Foram coletados resíduos do processamento de goiaba vermelha, cedidos por indústrias produtoras de polpa congelada de frutas da cidade de Fortaleza-Ce. Os resíduos, depois de levados à temperatura ambiente, foram desidratadas em estufa de circulação forçada do ar a $65{ }^{\circ} \mathrm{C}$ por $60 \mathrm{~h}$. Em seguida foram triturados e peneirados para obter-se uma granulometria variando entre 1,0 e 1,4 mm. Os produtos em pó foram armazenados em recipientes fechados, envoltos em papel alumínio e filme de PVC (policloreto de vinila) à temperatura ambiente.

O teor de Acido Ascórbico será determinado por meio do método titulometricos baseado na redução do indicador 2,6-diclorofenolindofenol pelo ácido ascórbico (BRASIL, 2005 b). Para a determinação da Acidez Titulável, titulou-se a amostra com solução de $\mathrm{NaOH}$ 0,1 Mol.L $\mathrm{L}^{-1}$, usando fenolftaleína como indicador (SILVA et al, 2004). Para a analise de cinzas as amostras calcinadas a $550^{\circ} \mathrm{C}$, por aproximadamente uma hora, até atingir cinzas brancas. A análise do $\mathrm{pH}$ foi realizada em pHmêtro, previamente calibrado com tampão de pH 4,0 e 7,0, de acordo com as normas analíticas de Brasil para amostras sólidas (SILVA et al, 2004). Os valores de atividade de água (Aw) seram determinados através do medidor de Aw da marca Aqualab by decagon. O teor de umidade foi analisado, atraves da secagem em estufa a $105^{\circ} \mathrm{C}$ por aproximadamente 24 horas (Instituto Adolfo Luts, 2008).

Os minerais foram quantificados por espectrometria de absorção atômica com chama (modelo ATOMICA-GBC 933 PLUS), calibrado em condições específicas de comprimento de onda.

A capacidade antioxidante foi determinada total pelo método ABTS com algumas modificações. Os polifenóis totais foram determinados de acordo com a metodologia descrita por Reynertson et al. (2008), utilizando o reagente Folin-Ciocalteau. A determinação dos carotenoides totais foi realizada apartir da solução extratora acetona: hexano (4:6).

O oxalato total foi quantificado pela titulação com permanganato de potássio (DAY e UNDERWOOD, 1986).

Os ingredientes utilizados na elaboração dos bolos estão representados na tabela 1 .

Tabela 1 - Lista de ingredientes utilizados no preparo das amostras A, B e C, e suas respectivas quantidades.

\begin{tabular}{cccc}
\hline Ingredientes & Amostra A & Amostra B & Amostra C \\
\hline Açúcar (g) & 360 & 360 & 360 \\
Manteiga (g) & 45 & 45 & 45 \\
Ovos (unidades) & 4 & 4 & 4 \\
Leite sem lactose (mL) & 240 & 240 & 240 \\
Farinha de trigo com fermento (g) & 360 & 324 & 252
\end{tabular}



36 108

Para o preparo da amostra adicionou-se em uma batedeira aproximadamente o açúcar, a manteiga, os ovos batidos em clara e neve, leite, a farinha de trigo com fermento e, no caso das amostras B e C a farinha de resíduo de goiaba. Misturaram-se os ingredientes até obter uma massa homogênea. Levou-se ao forno pré-aquecido à temperatura de $240^{\circ} \mathrm{C}$ por 45 minutos.

As análises sensoriais foram realizadas no laboratório de análise sensorial da Universidade Federal do Ceará. A análise foi realizada com 60 provadores através de teste de aceitação. Os consumidores avaliaram as amostras quanto à textura, impressão global e sabor, utilizando o teste da Escala Hedônica Estruturada de nove pontos (PERYAM e PILGRIM, 1957). A intenção de compra foi avaliada através de uma escala de cinco pontos (MEILGAARD et al., 1991). Os dados da analise sensorial foram tratados estatisticamente através de análise de variância (ANOVA) com $\alpha=5 \%$, para testar diferença entre os resultados. A análise estatística foi realizada através do programa estatístico SAS (Statistical Analyses System), versão 9.1 (SAS, 2006).

\section{RESULTADOS E DISCURSÃO}

A tabela 2 mostra os resultados para as análises físico-químicas do pó-alimentício, nela pode-se verificar que a farinha proveniente dos resíduos de goiaba estudada apresentam altas concentrações de acido ascórbico. Ao compararmos com os valores de ingestão diária recomendada (IDR) que é de $60 \mathrm{mg}$ para adultos (INSTITUTO,2008), a amostra pode ser consideradas boas fontes de acido ascórbico, pois fornecem de $40,05 \%$ da IDR.

Tabela 2 - Valores de Acido Ascórbico, Acidez Titulável, pH, Aw e Sólidos Solúveis das farinhas proveniente de resíduos do processamento de goiabas.

\begin{tabular}{cc}
\hline \multirow{2}{*}{ Parâmetros (\% em base seca) } & Amostra \\
\cline { 2 - 2 } & Farinha de Goiaba \\
\hline Ac. Ascórbico $(\mathrm{mg} / 100 \mathrm{~g})$ & $24,03 \pm 3,40$ \\
Acidez (g/100g) & $2,99 \pm 0,45$ \\
Sólidos Solúveis ( ${ }^{\mathrm{BRIX})}$ & $29,5 \pm 0,00$ \\
Umidade (\%) & $8,84 \pm 0,03$ \\
Cinza (\%) & $2,57 \pm 0,56$ \\
$\mathrm{pH}$ & $4,51 \pm 0,09$ \\
Aw & $0,27 \pm 0,03$ \\
\hline
\end{tabular}

Quanto a acidez, os valor encontrados na farinha foi de 2, $99 \mathrm{~g} / 100 \mathrm{~g}$ (Tabela 2). Ao analisar amostras de pós de caju e goiaba, Uchôa et al (2007) encontraram valores para goiaba cerca de 3 vezes menor $(1,21 \mathrm{~g} / 100 \mathrm{~g})$. Comparando os valores encontrados na análise de cinzas, verificou-se que a amostra analisada obteve teor de cinzas maiores que 1,00 g/100g (Tabela 2), pode-se supor que essa alta concentração de cinzas seja devido a alta concentração de minerais, que possivelmente esta presente nas 
amostras analisadas. $\mathrm{O}$ valore de $\mathrm{pH}$ encontrado foi de 4,051, enquanto a atividade de agua $\left(\mathrm{A}_{\mathrm{w}}\right)$ foi de 0,27 (Tabela 2). Esses valores tornam os produtos alimentos de difícil contaminação microbiana, visto que apresentaram $\mathrm{pH}$ fora da faixa de $\mathrm{pH}$ ótimo para crescimento microbiana (que é entre 6,5 e 7,5) e Aw abaixo de 0,85 valor considerado limite, abaixo do qual não há crescimento de bactéria patogênicas e fungos (UCHÔA, 2007).

O valor de sólidos solúveis totais foi de $29,5^{\circ}$ Brix.. Tais valores concordam com os encontrados por Sena et al. (2013), ainda em estudo com farinhas de resíduos de frutas encontrou valores de ${ }^{\circ}$ Brix variando entre 30,48 para amostras provenientes de goiaba vermelha e 10, 48 para amostras de goiaba branca. De acordo com os resultados encontrados, verificou-se que o teor de umidade $8,84 \%$, valores abaixo dos padrões exigidos pela legislação, mostrando eficiência np processamento de desidratação aplicado (SANTOS, 2012).

A figura 1 apresenta os resultados das análises de minerais realizadas no pó-alimentício obtidos a partir de resíduos do processamento de goiaba. Onde podemos observar que a amostra apresentou altos teores de mineris com destaque para o teor de $\mathrm{K}$ ( 488,92 mg/100g), representando cerca de 31,99\% da IDR pra um adulto (BRASIL, 2005).

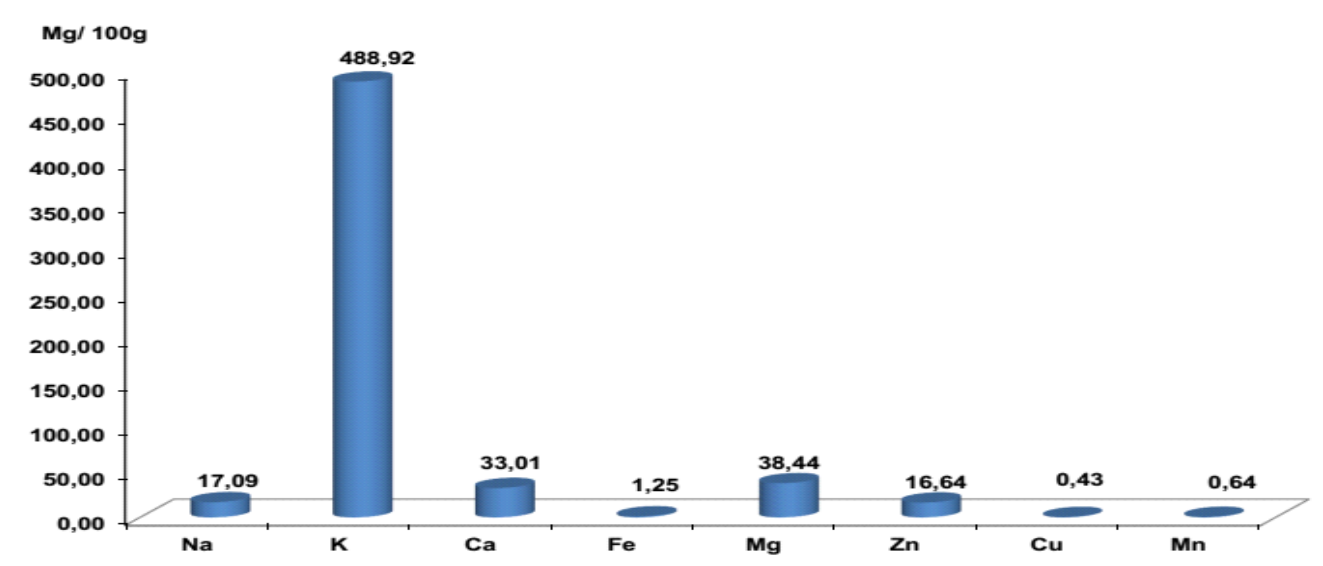

Figura 1- Teores de minerais no pó-alimentício provenientes de resíduos do processamento de goiaba.

Conforme o gráfico 1 pode-se verificar que, a amostra apresentou teor de sódio variaram 17,09 $\mathrm{mg} / 100 \mathrm{~g}$, vale importante ressaltar que a ingestão deste mineral (sódio) pela população é normalmente alta devido ao consumo de sal e alimentos processados e que teores elevados de sódio na dieta não são recomendados para pacientes hipertensivos (SOARES et al, 2004), Assim, as baixas concentrações desse mineral são benéficas.

Os teores de cálcio, foram de 33,01 mg/100g, esses valores consideráveis de cálcio são importantes para o uso do pó na elaboração de produtos sem lactose, uma vez que a dieta isenta de lactose resulta na menor absorção de cálcio (BARBOSA, 2011).

Os teores de magnésio variaram entre $38,44 \mathrm{mg} / 100 \mathrm{~g}$, comparando a IDR para este mineral as amostras correspondem a valores de aproximadamente $13,25 \%$ do indicado para este mineral que é de 
290mg por dia (BRASIL, 2005)

Como podemos observar no gráfico 1, a amostra apresentou concentração de ferro de 1,25 $\mathrm{mg} / 100 \mathrm{~g}$, este mineral é um componente fundamental da hemoglobina e de algumas enzimas do sistema respiratório e que a deficiência do mesmo na alimentação resulta em anemia (FELIPE, 2006).

As amostras em estudo apresentaram teores de cobre de $0,43 \mathrm{mg} / 100 \mathrm{~g}$, esses valores, quando comparados com a ingestão diária recomendada deste mineral para adultos Brasil, que é de $5 \mathrm{mg}$, esses valores representam $8,6 \%$ desta (BRASIL, 2005).

O teor de zinco presente na amostra foi de 16,64 mg/100g. De acordo com Soares et al. (2004), as faixas médias de ocorrência deste mineral (zinco) para os sucos concentrados de manga e maracujá, são, respectivamente, de: $0,24 \mathrm{mg} / 100 \mathrm{~g}$ e $0,70 \mathrm{mg} / 100 \mathrm{~g}$, sendo possível verificar que os teores encontrados neste estudo são superiores ao observado nos sucos concentrados para a amostra proveniente do resíduo de manga.

As amostras apresentaram teores de manganês entre 0,64 mg/100g. Segundo Soares et al (2004), em seu estudo da composição mineral de sucos concentrados, foram observadas as seguintes concentrações médias para o mineral manganês: $0,16 \mathrm{mg} / 100 \mathrm{~g}$ para o suco concentrado de manga e $0,11 \mathrm{mg} / 100 \mathrm{~g}$ para o suco concentrado de maracujá.

Conforme figura 2 a atividade antioxidante foi de $53,28 \mu \mathrm{g} / \mathrm{g}$, os valores correspondem à média de triplicatas. Kuskoski et al. (2006), também em estudo de atividade antioxidante em polpas de frutas, encontrou valores aproximados para polpa de acerola $(53,2 \mu \mathrm{mol} / \mathrm{g})$.

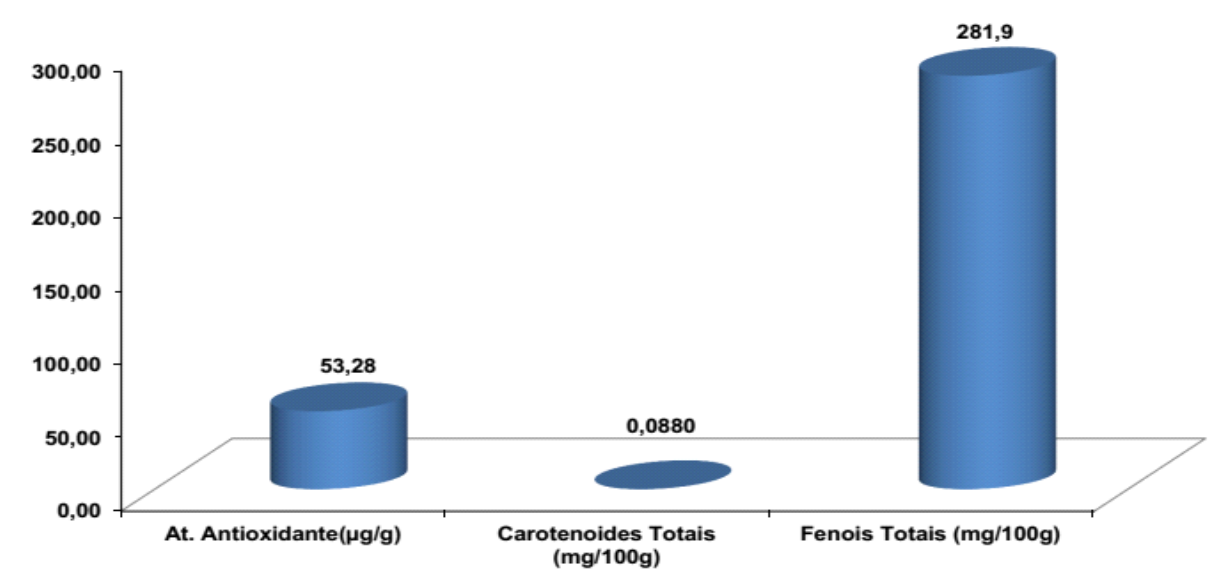

Figura 2 -Teores de atividade antioxidante, fenóis totais e carotenoides em amostra de farinha de resíduo de goiaba.

A amostra se destacou por seus altos teores de fenóis totais $(281,9 \mathrm{mg} / 100 \mathrm{~g})$, Tal fato torna as amostras interessante para a industrialização visto que a atividade antioxidante apresentada por vários vegetais esta correlacionada ao seu teor de compostos fenólicos totais (VELIOGLU et al., 1998). Os teores de Carotenoides encontrados, 0,088 mg/100g, valores inferior ao relatado Lima et. al. (2002).

Quando analisado o teor de oxalato, a amostra presentou uma concentração de 9,27 mg/100g, valor baixo sendo considerado insuficiente pra causar problemas na absorção de cálcio pelo organismo. 
De acordo com estudos, sugere-se que esses baixos valores podem ter sido influenciados pela temperatura a que foram submetidos os resíduos para a obtenção das farinhas (SANTOS, 2006).

Os resultados da analise sensorial estão dispostos na tabela 3.

Tabela 3 - valores médios das avaliações sensoriais bolo tipo fofo sem lactose com adição de pósalimentícios de goiaba em diferentes concentrações.

\begin{tabular}{cccccc}
\hline Concentração do pó & Aroma & Cor & Sabor & Textura & $\begin{array}{c}\text { Intenção de } \\
\text { Compra }\end{array}$ \\
\hline $\mathbf{0 \%}$ & 5,86 & 7,52 & 7,17 & 6,72 & 3,81 \\
$\mathbf{1 0 \%}$ & 6,65 & 6,52 & 6,78 & 5,07 & 3,12 \\
$\mathbf{3 0 \%}$ & 6,92 & 6,63 & 6,88 & 5,23 & 3,2 \\
\hline
\end{tabular}

No atributo aroma a amostra que obteve maior aceitação foi a amostra $C(6,92)$ já nos demais requisitos a amostra A (padrão), apresentou maiores médias, no entanto, os resultados da ANOVA a $5 \%$ de probabilidade indicaram não haver diferença entre as médias de todos os atributos avaliados no teste de aceitação sensorial para as diferentes formulações de bolo fofo testadas, assim, a adição de farinha de resíduo de goiaba nas proporções testadas não afetou a aceitação sensorial dos bolos para os atributos cor, textura, sabor e intenção de compra

Considerando que ao se desenvolver um novo produto, um dos pontos fundamentais é avaliar sua aceitabilidade, a adição de farinha de resíduos de goiaba nas quantidades testadas não modificou a formulação do bolo de forma a alterar a sua aceitação, Tal resultado é semelhantes aos encontrados em outros estudos. INTROVINI et al. (2008) avaliaram a aceitação sensorial de bolos de chocolate marmorizado com coco sem lactose e sem glúten e constataram que a cor, aparência e textura não diferiram da formulação padrão contendo lactose e glúten.

\section{CONCLUSÕES}

Concluiu-se que a adição de farinha de resíduo de goiaba nas proporções testadas não afetou a aceitação sensorial dos bolos para os atributos cor, textura, sabor e intenção de compra. Assim, os bolos adicionados de farinha resíduos de goiaba nas quantidades avaliadas neste estudo possuem qualidade sensorial similar à formulação padrão (formulação A) e com a vantagem de possuírem uma maior qualidade nutricional.

\section{REFERÊNCIAS}

ABUD, A. K. S.; NARAIN, N. Incorporação da farinha de resíduo do processamento de polpa de fruta em biscoitos: uma alternativa de combate ao desperdício. Brazilian Journal of Food Technology, v. 12, n. 4, p. 257-265, 2009.

BARBOSA,C.R.;ANDREAZZI,M.A. Intolerância À Lactose E Suas Consequências No Metabolismo Do Cálcio. Saúde e Pesquisa, v. 4, n. 1, p. 81-86, jan./abr. 2011 
SILVA, M.R.; SILVA, M.S.; OLIVEIRA, J.S. Estabilidade De Ácido Ascórbico Em Pseudofrutos De Caju-Do-Cerrado Refrigerados E Congelados. Pesquisa Agropecuária Tropical, V. 34, N. 1, P. 9-14, 2004.

SILVA, m.b.l.; BERALDO, j.c.; DEMATEI, 1.r. Efeito Da Adição De Farinha De Linhaça Na Aceitação Sensorial De Bolo De Chocolate. Centro Científico Conhecer - ENCICLOPÉDIA BIOSFERA, Goiânia, vol.5, n.8, 2009.

SOARES, L.M.V. et al. Composição mineral de sucos concentrados de frutas brasileiras. Ciências e Tecnologia de alimentos, Campinas, v.24, n.2, p.202-206, abr/jun. 2004.

UCHOA, M. A. Adição de pós-alimentícios obtidos de resíduos de frutas tropicais na formulação de biscoitos. 2007. 89 f. Dissertação (Mestrado em Tecnologia de Alimentos) - Curso de Pós-Graduação em Tecnologia de Alimentos, Universidade Federal do Ceará, Fortaleza, 2007.

VELIOGLU, Y.S.; MAZZA, G.; GAO, L.; OOMAH, B.D. Antioxidant activity and total phenolics in selected fruits, vegetables, and grain products. Journal of Agricultural and Food Chemistry, v.46, p.4113-4117, 1998. 